\title{
THE ROLE AND IMPORTANCE OF MENTORING IN PHYSIOTHERAPY
}

\begin{abstract}
Numerous opportunities are afforded by mentoring for career development, new knowledge, stronger theoretical and practical foundations, as well as development of leadership and problem-solving skills. In physiotherapy, mentoring as relates to practice, education and research will help to ensure the growth and future of the profession. Mentoring can be utilised in many different instances in the teaching and learning cycle of physiotherapy students and physiotherapists and can contribute towards

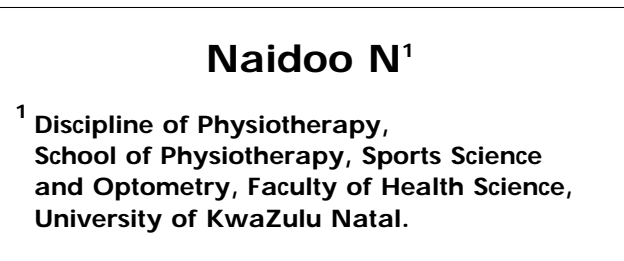
professional growth. The benefits derived by the mentor and mentee are immense if implemented in accordance with a deep understanding of the mentoring process.

The mentoring process needs to be based on intelligent reading of situations and action by the mentor and mentee for a successful relationship. Each mentoring connection is unique, therefore each person enters the relationship and process with their own values and expectations. Mentoring practices are an effective way of supporting and fostering development throughout the duration of the undergraduate physiotherapy programme, and professional and career development of physiotherapists.

This article reviews the process of mentoring and its importance for implementation in physiotherapy, for undergraduate training and physiotherapy professional growth.
\end{abstract}

\section{KEY WORDS: MENTORING, FEEDBACK, COUNSELLING, REFLECTION, LEARNING.}

\section{INTRODUCTION}

Cultural diversity, insight into student variety, learning styles and the pace of students' learning has led to changes in the conditions and learning needs of students and staff at tertiary institutions. Concurrently, there is a plethora of subject-matter and knowledge about teaching and learning. This has afforded numerous opportunities for mentoring for career development, stronger theoretical and practical foundations, development of leadership and problem-solving skills. A key challenge for the allied health professions is to evolve organisational models which preserve attributes valued by the professions (Boyce,

\section{CORRESPONDENCE TO:}

Nirmala Naidoo

Discipline of Physiotherapy

School of Physiotherapy,

Sports Science and Optometry,

Faculty of Health Science

University of KwaZulu Natal

Private Bag X54001

Durban 4000

South Africa

Tel: (031) 260-7817

Fax: (031) 260-8106
1996). Physiotherapy educators must be responsive to societal changes and modify curricular approaches to better prepare students to work effectively as an interdisciplinary team (Glass and Walter, 2000). In physiotherapy, mentoring with regards to practice, education and research will help to ensure the growth and future of the profession (Gandy, 1993).

Maudsley and Strivens (2000) advocated that experiential learning facilitates higher order thinking and problem-solving. Mentoring, if implemented with this understanding, would facilitate learning in physiotherapy. It is an important mode of professional development where the underlying assumption is that a more experienced colleague can facilitate the professional development of a younger colleague (Bush and Coleman, 2004). This can have a positive impact on the quality of physiotherapy service and our future as a profession. Mentoring students, especially those entering the physiotherapy programme, may be an effective means of achieving the outcomes of the undergraduate physiotherapy programme. Mentoring of staff and staff development programmes should be supported for personal and career development.

\section{DIFFERENT ROLES OF THE MENTOR}

A mentor should have several roles and mentor-mentee interactions should ultimately enhance the reflective abilities of both participants (Kolb, 1984). Mentoring is far more encompassing than the individual roles and each has the potential to develop into a mentoring relationship (Gandy, 1993).

The mentor role of counsellor (someone who provides moral support in times of stress) is important (Robertson, 1992). This requires a trusting and open relationship with confidentiality and mutual respect (Tomlinson, 1995). Mentors could provide students with counsel for personal issues which may present and thereby enhance performance. The perceived advantage for the educational institution is the opportunity to increase the professional network. Hard-earned knowledge and skills are transferred to younger colleagues and this could improve the overall performance of the group.

Another mentor role is that of teacher; someone who enhances skills and intellectual development (Gandy, 1993). Mentoring involves diverse and multiple activities through which the more experienced teacher leads a novice 
to new understanding and skills and shares experiences as a seasoned professional (Hawkey, 1997).

The mentor should be an exemplar; someone whom the mentee can seek to emulate (Sands et al, 1991). As a role model the mentor must ensure an example of good values, ethics and professional practices (Robertson, 1992). A "role model" is someone who demonstrates how a job is performed and a "mentor" is a 'personalised' role model who acts as a guide, coach and confidant (Bolton, 1980).

Maudsley and Strivens (2000) contend the importance of motivation; the inner drive that compels a person to succeed and maybe necessary to unleash individual potential that the mentor should recognise and encourage. The authors advocate that the most effective way to encourage a mentee is to provide positive feedback, give support during an assigned task or while the mentee strives toward a goal. Positive feedback boosts morale, self-confidence and esteem.

Another role is adviser; one who is regularly consulted and who advises students (Oxford English Dictionary, version 2). This is where the mentor helps develop the mentee's professional interests and sets goals which should be specific, time-framed, result-orientated and attainable (Calderhead, 1993).

\section{ADVANTAGES OF MENTORING IN PHYSIOTHERAPY}

A mentor helps the mentee create a sense of identity as a member of the profession (McCormick and Titus, 1990). Effective mentoring would facilitate networking by decreasing professional isolation and the sharing of experiences would assist in developing common values (Daresh and Playko, 1992).

Research has demonstrated that mentorship results in student-centred learning (Spouse, 1996), creates dialogue about practice (Porter, 1989), promotes professional development in the adult mentor (Cahill and Kelly, 1989), stimulates reflection and results in augmented learning (Hayward et al, 2005). This would yield increased productivity, improved skills, refined leadership qualities and improved performance. It covers holistic support by incorporating interpersonal, psychosocial development, career and educational development, and socialisation functions (Carruthers, 1992).

Mentoring in physiotherapy is a good strategy to promote growth and development (Sands et al, 1991).The development of formal mentoring relationships could assist in strengthening efforts in practice, education and research in physiotherapy. Redmond (1990) examined the role of planned mentoring and claims that it can increase retention and graduation rates of culturally diverse students. This could provide opportunities for enhancing cultural diversity within the profession.

\section{DISADVANTAGES OF MENTORING}

A successful mentoring relationship requires significant time commitment (Gandy, 1993). This may present as a disadvantage especially if both have busy schedules. There is the possibility of a "mismatch" between mentor and mentee leading to an unsuccessful relationship. There is no direct measurable outcome making it difficult to assess the resources required to achieve mentoring goals.

Ill-defined roles could complicate the mentoring relationship and process. When goal-setting and definite objectives are not determined at the outset, one or both may fail to see the direction of the other (Robertson, 1992). The mentor's approach to change could have a negative influence because mentors may have their own theories and may not be amicable to alternatives (McCormick and Titus, 1990).

The manner in which critique is metered out could influence the mentee's performance (Bolton, 1980). This could result in the mentee's failure to react appropriately to the critique. Additionally, the mentee may accept the mentor's suggestion and implement change without question and this could stifle the development of the mentee's ideas, which opposes reflective teaching and learning. The process is difficult and challenging particularly relating to professional regard and the follow-up relationship (Boyce, 1996).

\section{PRE-REQUISITES OF MENTORSHIP}

Support, guidance, reaching of agreement, method, mode and strategy are required to achieve positive results (Caldwell, 1993). This can be achieved by setting up mutually agreed strategies and mechanisms beforehand on how the mentoring process would work best thereby creating a dynamic and interactive process (Feiman-Nemser and Rosean, 1997; Cottingham, 2002). Positive influence is provided by the mentor to assist the mentee's progress, influence the direction and quality of learning and thereby achieve the desired outcome (Hayward et al, 2005).

Cohen (1995) suggested that the timing of the mentee's comments is important in the promotion of meaningful personal reflection. This is a pre-requisite for trust and sets the foundation. The requirements for good mentorship are the need to agree on mentor and mentee roles and to sincerely encourage the relationship. Success depends on the individuals' involvement and their affinity for each other and their work (Feiman-Nemser and Rosean, 1997).

\section{Steps in the mentoring process}

Robertson (1992) proposed questions for consideration when contemplating a mentoring relationship:

- What tangible and intangible rewards do you expect?

- What are your goals for your personal and professional development that can be addressed?

- What time do you anticipate dedicating to the mentoring relationship?

- How long do you need to be in the relationship to reach your desired outcome?

Tomlinson (1995) proposed the following steps in the mentoring process:

i) Planning - The mentor and mentee should establish the mentee's goals and determine mutually agreed upon strategies, approaches, decisions, time-frames, meeting venues and personal issues. The mentor must however guard against mentee dependency while primarily attempting to assist and guide the mentee to foster personal challenge and to work together on collaborative reflection (Hawkey, 1997). The cumulative objective of planning is to create a foundation on which both 
can mutually plan towards their goals (Bolton, 1980).

ii) Engaging - The process of engaging includes the objectives and goals preset by both and mutually agreed upon (Jacques, 1993).

iii) Monitoring - Some form of assessment of the mentorship process needs to be in place to establish quality control. This is challenging as measurement of the process is difficult to quantify, but important to determine success or not for both (Zachary and Laurent, 2000).

iv) Feedback - Regular feedback by both participants is necessary to keep on track of the mentoring process and to ascertain whether the discussed goals and objectives are being met.

The mentoring process equips mentees to realise their potential as successful and productive individuals. This process therefore implies integration and transfer of necessary skills, knowledge, behaviours and attitudes that will result in the mentee's success.

\section{Aims and goals of mentorship}

Mentorship should empower the mentee into reflective activities and self-correction which are characteristic of the learning process (Henderson, 1992). The mentor should aim to develop the mentee into a confident learner, who draws on the interpersonal skills of the mentor (Cohen, 1995).

The activities mentors choose depend on their understanding of the work, mentee's needs, nature of the experience and other responsibilities. Feedback and reflection should promote growth of the mentee (Hawkey, 1997).

\section{SPECIFIC ROLE OF THE MENTOR IN MENTORING UNDERGRADUATES}

Learning that occurs outside the classroom is more memorable and much of the value in undergraduate education can come from such interactions (Light, 2001). From the students' point of view, a high quality mentoring system could produce important outcomes (Light, 2001):

- Perceived needs would be understood and appreciated, and students would be referred to appropriate resources.
- Students would be guided through the network of people at their respective institutions who could provide more focussed, specialised advising, including career advice, professional contacts.

- Students would have high quality one-on-one personal interactions with staff

- Students would know staff and vice versa in order to obtain recommendation.

- Students could actively engage in developing their educational plans which evolves over time in response to their changing needs, instead of merely receiving advice (Zachary and Laurent, 2001).

It is critical that the mentor be aware of the mentee's pace of learning. The mentor must be alert, flexible and be prepared to make adjustments for differences in individual maturity and learning style (Cohen, 1995). It is important to pre-set the commitment of students (Cohen, 1995). Teaching and clinical practice are more than what actually goes on in the direct encounter between students, content and lecturer (Handal, 1987). It includes planning and evaluation activity which comes before and after this encounter and refers to the teaching strategies and underlying practical theory of the teacher concerned which could impact on the quality of the mentoring experience.

\section{MENTORING POSTGRADUATES}

Caldwell (1993) held the argument that mentees become more independent with time with the frequent outcome of lifelong friendship. Henderson (1992) proposed that the exemplary teacher strives for continuing personal professional growth. The mentoring process therefore would support personal-professional growth thereby facilitating exemplary students and therefore growth of graduates, which could impact on the physiotherapy profession.

Cottingham (2001) suggests practice sessions and one-on-one sessions with the graduate student and mentor. The examples stated include academic writing, career paths, issues of postgraduate supervision, teaching and managing issues of networking especially relating to issues of developing key skills within research. Dunleavy (2004) advocates that the physiotherapist's profession grows as specialised clinical skills are acquired, and the less experienced physiotherapist, the patient and thus the profession all gain from the relationship.

\section{CONCLUSION}

The mentor-mentee relationship is a learning activity essentially created for the mentee's benefit, with the mentor functioning as a guiding but not controlling influence on the mentee's choices and goals. The mentor therefore assumes responsibility for promoting a transactional process of learning, which involves active participation with a mentee as a collaborative partner in learning. This sets the stage for success and could contribute to a long-lasting friendship on either a professional or social basis, or both.

Effective mentoring fosters personal and professional development and has the potential to assist both physiotherapy students and graduate professionals through the process of caring, sharing and helping to achieve personal effectiveness, motivation and commitment. Thus, mentoring relationships could facilitate the development of the physiotherapy profession as a whole. Essential skills for physiotherapists can be enhanced to impact the broader environment such as community service, public and private funding sources, institutions of higher education and other bodies associated with physiotherapy, such as the Health Professions Council of South Africa and The South African Society of Physiotherapy. Mentoring can have a tremendous effect on practice, education and research by empowering professionals to work individually and with others towards more perceptive and reflective practice. Mentorship is a professional behaviour that serves the individuals' profession and members of the society we serve and can be the key to job satisfaction and creation of a sense of community among professionals. 


\section{REFERENCES}

Bell K 2003 Mentoring as improvisation. Unpublished dissertation. East Lansing, Michigan State University, Department of Teacher Education.

Bolton EB 1980 A conceptual analysis of the mentor relationship in career development of women. Adult Education, 30; 195-207

Boyce R 1996 Researching the organisation of Allied Health Professionals. Invited address to 2ND National Allied Health Conference, Sydney, Australia.

Bush T, Coleman M 2004 Professional development for heads: The role of mentoring.Journal of Educational Administration; 2: $60-74$

Caldwell BJ 1993 The return of the mentor: Strategies for workplace learning. Falmer Press. Bristol.

Calderhead J 1993 Conceptualising reflection in teacher development. Washington DC. Falmer Press.

Carruthers J 1992 Principles and practice of mentoring. Krieger Publishing Company. Florida.

Clutterbuck D1992 Mentoring. Henley Distance Learning, Henley.

Cohen NH 1995 Mentoring adult learners. M.W. Galbraith. Krieger Publishing Company. Florida

Cottingham K 2002 Mentoring scientists: An ethical dilemma. Ethics in Science, 4; 36-40
Dunleavy JM 2004 Mentorship: A matter of professional responsibility. Physiotherapy Magazine March 2004.

Daresh JC, Playko MA 1992 Mentoring of head teachers: A review of major issues. School Organisation, Vol 12: 2: 145-52

Feiman-Nemser S, Rosean C 1997 Guiding teacher learning. In S. Feiman-Nemser and C.Rosean (Eds.). Insider studies of classroom work with prospective and practicing teachers. Washington DC. AACTE Publications pgs. 7-36.

Gandy J 1993 Mentoring. Orthopaedic Practice, 5; 6-9

Glass N, Walter R 2000 An experience of peer mentoring with student nurses: Enhancement of personal and professional growth. Journal of Nursing Education, 2000; 39: 155-159

Handal G 1987 Promoting reflective teaching. Clarke Williams. Great Britain.

Hawkey K 1997 Roles, responsibilities and relationships in mentoring: A literature review and agenda for research. Journal of Teacher Education, 48 (5); 325-335

Hayward LM, Canali A, Hill A 2005 Interdisciplinary peer mentoring: A model for developing culturally competent health care professionals. Journal of Physiotherapy Education.

Jacques P 1993 Small group teaching. Great Britain. Kogan Page.

Kolb D 1984 Learning how to mentor. Uswe and Juta. New Jersey.
Light R 2001 Making the most of college: Students speak their minds. Harvard University Press, Cambridge. USA.

Henderson JG 1992 Reflective teaching: Becoming an enquiring educator. Macmillan Publishing Company. New York.

Maudsley G, Strivens J 2000 Promoting professional knowledge, experiential learning and critical thinking for medical students. Medical Education, 34: 535-544

Spouse J 1996 The effective mentor: A model for student-centred learning. Nursing Times; 92:32-35

Sweeny B 2004 Advantages of mentoring. www.mentoring.com (Accessed February 2005).

McCormick TE., Titus P 1990 Mentoring: Giving minority women tools for advancement. Mentoring International, 4; 31-37

Robertson SC 1992 Find a mentor or be one. The American Occupational Therapy Association, Inc., USA pg.5

Redmond SP 1990 Mentoring and cultural diversity in academic settings. American Behavioral Scientist, 34; 188-200.

Sands RG, Parson LA, Duane J 1991 Faculty mentoring faculty in a public university. Journal of Higher Education, 62; 174-193.

Tomlinson P. 1995 Understanding mentoring. Philadelphia. Open University Press.

Zachary JL, Laurent AD 2000 The mentor's guide: Facilitating effective learning relationships. Jossey-Bass. Melbourne.

\section{CAUNG FOR NOMINATIONS}

FOR A NEW EDITORIAL BOARD AND REVIEW PANEL

ince the editor has moved from $\mathrm{G}$ auteng to the W estern $S$ Cape it has become clear that the administrative office for the South African Journal of Physiotherapy should ideally also be located there. After lengthy discussions with academic and administrative personnel as well as the Executive of the SASP a decision was made to relocate the office for the Journal to Mossel Bay. It was also decided to establish a new Editorial Board with representation mainly from the Western Cape as that would make regular contact meetings more realistic. At the same time it was decided that we would also consider the status of the review panel.

Both the current Editorial Board as well as the Review Panel did well under difficult conditions. It was particularly difficult because due to economic restrictions it was not possible to meet in person and the only way of communicating was through teleconferences which made the interaction unsatisfactory. Teleconferences were poorly supported because of the high level of demand on the members who were mostly academics. We are hoping to include more clinicians on our Editorial Board and Review Panel in the future.

Meetings for the Journal will be held in Cape Town and the new Editorial Board will consider the purpose and goals of the Journal, the structure and function of the Editorial Board as well as that of the Review Panel. The review process will also be discussed and finalised.

We request interested academics and clinicians to put forward their names as well as names of other suitable candidates for positions on these two committees. Submissions must be made to the Journal editor as soon as possible supported with the CV of the nominee. 